\title{
Gender Differences among the Muslims with Respect to Emotional Intelligence
}

\author{
Indelah $\mathrm{Khan}^{1}$, A. K. Kapoor ${ }^{2}$
}

\section{ABSTRACT}

Neuro anthropology is a broad area of Applied Anthropology that studies and embraces different modalities and structures of human neural activity like emotion, perception, cognition and motor control. Emotional Intelligence involves the ability to monitor one's own and others feelings and emotions to discriminate among them and to use information to guide one's thinking and actions. It aids in predicting success in social settings because it shows how a person deals with the daily challenges and applies knowledge to the immediate situations. Emotional Intelligence is thus, an important factor in ascertaining one's capability in successfully dealing with environmental demands and pressures and shape one's psychological health status, involving overall emotional health.

Keywords: Neuroanthropology, neural activity, emotions, emotional intelligence, Psychological health

Neuro anthropology explores and studies the interaction of culture and brain for the understanding of mind, behavior and self. Neuro anthropology builds in-depth analysis of mind, behavior and self based on an understanding of self of both neurological functions and ethnographic reality.

Emotions are regarded as the basic function of human life and thus have been placed at the centre of human psyche. We believe that Emotional Intelligence is contrived from the set of emotional information. Emotions have a tendency to transmit a unique and diverse set of emotional signals. Emotions guide, signal and prompt responses to varied situations, which direct us in a direction that has worked in a desirable way, managing and coping the daily tests of human life. Emotional Intelligence can be stated as our capacity to recognize our own feelings and those that of others, to handle emotions of oneself and that of others. The various faculties of Emotional Intelligence are:

- Ability to perceive emotion;

- Use emotion to facilitate thought;

\footnotetext{
${ }^{1}$ Research Scholar, Department of Anthropology, University of Delhi Delhi-7, India

${ }^{2}$ Professor, Department of Anthropology, University of Delhi, Delhi-7, India

*Corresponding Author

(C) 2015 I I Khan, A Kapoor; licensee IJIP. This is an Open Access Research distributed under the terms of the Creative Commons Attribution License (http://creativecommons.org/licenses/by/2.0), which permits unrestricted use, distribution, and reproduction in any Medium, provided the original work is properly cited.
} 


\section{Gender Differences among the Muslims with Respect to Emotional Intelligence}

- Understand emotion; and

- Manage emotion

The first branch of Emotional competencies reflects the degree of perception of emotion and involves the capacity of recognizing emotions in others through body language i.e., facial and postural expressions. It involves non-verbal perception of emotion and expression of emotion in the face, voice, and other related channels of communication.

The second branch pertains to the assessing of strength of emotions to assist the thinking patterns of human beings. The knowledge of the thread linking emotional component with thinking pattern, assists in channelizing towards better planning.

The third branch points towards the understanding of emotion, demonstrate the capacity to analyze the feeling component, value their probable trends over time and understand their outcomes.

The fourth branch focuses on the strength of management of emotions, which involves the rest of personality, i.e., emotions are managed and dealt taking into consideration, the individual's aspirations, knowledge and understanding of self and social awareness. By the time, early adulthood is attained, the means of self-management skills also inhances which includes acquiring the abilities, to avoid feelings or to reframe appraisals to reassure oneself or achieve equanimity.

\section{REVIEW OF LITERATURE}

The concept of emotional intelligence proposed by Salovey and Mayer (1990) was defined as “the ability to monitor one's own and others' feelings and emotions, to discriminate among them and to use this information to guide one's thinking and actions. Mayer and Salovey (1997) identified four components of emotional intelligence, involving emotional perception, emotional facilitation, emotional understanding and emotional management.

Mayer et al, (1996) undertook a study to determine correlation of emotional intelligence with the identification of emotions for which three hundred and twenty one participants were included in the study which were required to read the writings of a target group of people and guess what those targets had felt. Several criteria were used to evaluate the participant's emotional recognition abilities, including agreement with the group consensus and agreement with the target. Thus the results came out as, participants who agreed more highly with the group consensus and with the target also scored higher than the other participants on scales of empathy and self-reported SAT scores, and lower o emotional defensiveness. People who are good at connecting thoughts to feelings may bette 'hear' the emotional implications of their own thoughts, as well as understand the feelings of others from what they say. 


\section{Gender Differences among the Muslims with Respect to Emotional Intelligence}

Ciarrochi et al, (2002) carried out research study to verify the hypothesis that emotional intelligence EI would make a unique contribution to understanding the relationship between stress and three important mental health variables, depression, hopelessness, and suicidal ideation. University students $(n=302)$ participated in a cross sectional study that involved measuring life stress, objective and self-reported emotional intelligence, and mental health. Regression analyses revealed that stress was associated with: (1) greater reported depression, hopelessness, and suicidal ideation among people high in emotional perception (EP) compared to others; and (2) greater suicidal ideation among those low in managing others' emotions (MOE). Both EP and MOE were shown to be statistically different from other relevant measures, suggesting that EI is a distinctive construct as well as being important in understanding the link between stress and mental health.

Brackett et al,(2004) conducted the following research to examine relations between Emotional Intelligence and everyday life conditions. Emotional intelligence was measured as an ability by the MSCEIT, life conditions were conditions were measured by a scale of life space, the (CSLSS) that assessed an array of self-care behaviours, leisure pursuits, academic activities and interpersonal relations, for which college students $(\mathrm{N}=30)$ were employed into the study. The results interpreted as women scored significantly higher in EI than in males. EI, however was more predictive of the Life Space criteria for men than for women. Lower EI in males,

principally the inability to perceive emotions and to use emotion to facilitate thought, was associated with negative outcomes, including illegal drug and alcohol use, deviant behaviour, and poor relations with friends. Thus EI was significantly associated with maladjustment and negative behaviours for college-aged males, but not for females.

Noorbakhsh et al,(2010) carried out the research study with the aim to examine the relationship between emotional intelligence (EI) and coping styles with stress in a sample of students. Four hundred and thirteen students (140 males, 273 females) were included in this study. Multivariable variance analysis test, for comparison of male and female students showed that male students were not meaningfully different in any of the subscales of EI and coping styles. Results of Pierson correlation showed that EI has positive relation with problem-focused coping, positive emotional-focused coping style. Increase emotional productivity or facilitating emotional and evaluation and reduce using negative emotional-focused coping style.

\section{MATERIAL AND METHODS}

The present study has been carried in a population group of Muslims, both males and females of Allahabad, Uttar Pradesh. The sample size taken was 157 i.e.,62 males and 95 females and their age being 18-60 years. Set of standardized interview schedule was incorporated as the mode of data collection. 


\section{RESULTS AND DISCUSSION}

Based upon the psychological variable namely 'Emotional Intelligence', the inter-variation between males and females were obtained:

Table1: Distribution of Muslims based on their responses as to how difficult do they find, listing their strengths.

\begin{tabular}{|l|c|c|c|c|c|c|c|}
\hline Gender & & Always & Mostly & Sometimes & Never & Can't say & Total \\
\hline Males & $\mathrm{N}$ & 10 & 8 & 19 & 23 & 2 & 62 \\
\hline & $\%$ & 16.1 & 12.9 & 30.6 & 37.1 & 3.2 & 100 \\
\hline Females & $\mathrm{N}$ & 14 & 22 & 31 & 27 & 1 & 95 \\
\hline & $\%$ & 14.7 & 23.2 & 32.6 & 28.4 & 1.1 & 100 \\
\hline
\end{tabular}

Table1 shows maximum proportion of Males i.e.,37.1\% don't find it difficult in coming up with their strengths whereas in contrast to males, major proportion of females i.e.,32.6\% 'sometimes' finds it difficult in talking about their strengths.

Table2: Distribution of Muslims based on their responses as to how much adjustment do they make, when interacting with people.

\begin{tabular}{|l|c|c|c|c|c|c|c|}
\hline Gender & & Always & Mostly & Sometimes & Never & Can't say & Total \\
\hline Males & $\mathrm{N}$ & 24 & 15 & 15 & 7 & 1 & 62 \\
\hline & $\%$ & 38.7 & 24.2 & 24.2 & 11.3 & 1.6 & 100 \\
\hline Females & $\mathrm{N}$ & 36 & 38 & 16 & 5 & 0 & 95 \\
\hline & $\%$ & 37.9 & 40.0 & 16.8 & 5.3 & 0 & 100 \\
\hline
\end{tabular}

Table 2 shows maximum proportion of Males i.e.,38.7\% 'always' make efforts to adjust well in a gathering of people, similarly major proportion of females i.e.,37.9\% too, well adjust in a social setting.

Table 3: Distribution of Muslims based on their responses as to how much do they avoid talking about sensitive issues.

\begin{tabular}{|l|c|c|c|c|c|c|c|}
\hline Gender & & Always & Mostly & Sometimes & Never & Can't say & Total \\
\hline Males & $\mathrm{N}$ & 9 & 18 & 20 & 14 & 0 & 62 \\
\hline & $\%$ & 14.5 & 29.0 & 32.3 & 22.6 & 0 & 100 \\
\hline Females & $\mathrm{N}$ & 26 & 33 & 26 & 10 & 0 & 95 \\
\hline & $\%$ & 27.4 & 34.7 & 27.4 & 10.5 & 0 & 100 \\
\hline
\end{tabular}

Table 3 shows maximum proportion of Males i.e.,32.3\% ‘sometimes' prefer to avoid talking about sensitive issues whereas major proportion of females i.e.,34.7\% 'mostly' postpone or avoid discussing sensitive issues. 
Table 4: Distribution of Muslims based on their responses as to how frequently do the start linking one negative thought with that of other.

\begin{tabular}{|l|c|c|c|c|c|c|c|}
\hline Gender & & Always & Mostly & Sometimes & Never & Can't say & Total \\
\hline Males & $\mathrm{N}$ & 4 & 13 & 23 & 21 & 1 & 62 \\
\hline & $\%$ & 6.5 & 21.0 & 37.1 & 33.9 & 1.6 & 100 \\
\hline Females & $\mathrm{N}$ & 13 & 23 & 24 & 35 & 0 & 95 \\
\hline & $\%$ & 13.7 & 24.2 & 25.3 & 36.8 & 0 & 100 \\
\hline
\end{tabular}

Table 4 shows maximum proportion of Males i.e.,37.1\% 'sometimes' starts linking one negative thought with another, whereas a major percentage of females i.e.,36.8\% does not seem to connect one negative thought with that of another.

Table 5: Distribution of Muslims based on their responses as to how much do they express their views in front of people, who would disagree with them.

\begin{tabular}{|l|c|c|c|c|c|c|c|}
\hline Gender & & Always & Mostly & Sometimes & Never & Can't say & Total \\
\hline Males & $\mathrm{N}$ & 11 & 18 & 20 & 12 & 1 & 62 \\
\hline & $\%$ & 17.7 & 29.0 & 32.3 & 19.4 & 1.6 & 100 \\
\hline Females & $\mathrm{N}$ & 14 & 24 & 41 & 16 & 0 & 95 \\
\hline & $\%$ & 14.7 & 25.3 & 43.2 & 16.8 & 0 & 100 \\
\hline
\end{tabular}

Table 5 shows maximum proportion of Males i.e.,32.3\% 'sometimes' go ahead and express their views in front of people, even if they would disagree with them, similarly a major proportion of females i.e., $43.2 \%$ too believe in voicing their opinions in front of others.

Table 6: Distribution of Muslims based on their responses as to how frequently do they require a push from others, to get them going.

\begin{tabular}{|l|c|c|c|c|c|c|c|}
\hline Gender & & Always & Mostly & Sometimes & Never & Can't say & Total \\
\hline Males & $\mathrm{N}$ & 6 & 10 & 30 & 15 & 1 & 62 \\
\hline & $\%$ & 9.7 & 16.1 & 48.4 & 24.2 & 1.6 & 100 \\
\hline Females & $\mathrm{N}$ & 7 & 11 & 38 & 39 & 0 & 95 \\
\hline & $\%$ & 7.4 & 11.6 & 40.0 & 41.1 & 0 & 100 \\
\hline
\end{tabular}

Table 6 shows maximum proportion of Males i.e., $48.4 \%$ 'sometimes' require a push to keep them going whereas a major proportion of females i.e., $41.1 \%$ don't require backing from the people, to do something.

Table 7: Distribution of Muslims based on their responses as to how much do they take ethical reasons into consideration, before making any decision.

\begin{tabular}{|l|l|c|c|c|c|c|c|}
\hline Gender & & Always & Mostly & Sometimes & Never & Can't say & Total \\
\hline Males & $\mathrm{N}$ & 15 & 15 & 23 & 8 & 1 & 62 \\
\hline & $\%$ & 24.2 & 24.2 & 37.1 & 12.9 & 1.6 & 100 \\
\hline Females & $\mathrm{N}$ & 39 & 24 & 23 & 8 & 1 & 95 \\
\hline & $\%$ & 41.1 & 25.3 & 24.2 & 8.4 & 1.6 & 100 \\
\hline
\end{tabular}




\section{Gender Differences among the Muslims with Respect to Emotional Intelligence}

Table 7 shows maximum proportion of Males i.e., 37.1\% ‘sometimes' pay heed to the ethical considerations before taking any decision whereas a major proportion of females i.e.,41.1\% 'always' keep in mind the ethical consideration, before taking any important decision.

\section{CONCLUSION}

The present study is concerned with the Emotional Intelligence capacities and how well people can understand and recognise emotions of others and as well as that of themselves which can aid in everyday problem-solving situations. Thus, recognizing emotions, I directly proportional to a person's emotional well-being. Some of the important finding brought forth from the study included that males are more self assured about their personality strengths and weaknesses when asked upon as compared to the females. In situations o taking important life decisions or making choices, females keep in mind, the ethica considerations of their choices more than the males, which can be attributed to the higher levels of Emotional Intelligence in females. Higher level of Emotional Intelligence incase of females have also been supported by a previous research study undertaken by Brackett et al.

\section{REFERENCES}

Agarwal, D.\& kapoor,A.K.,2013.Cognitive Dynamics in an Ethnic group of North India. Int.J.of Social \& Allied Research (IJSAR);vol.1, No.3.

Agarwal, D.\& kapoor,A.K.,2013.The Emotion perspective of an Ethnic group of North India. Int.J.of Scientific Research publication;vol.3,issue 4.

Ciarrochi et al,2002. Emotional intelligence moderates the relationship between stress and mental health, Personality and Individual Differences,Vol.32, Issue 2, 19 Jan. 2002, Pages 197-209.

Daniel Goleman,1996. Emotional Intelligence: Why it can matter more than IQ, Bloomsbury Publishing, London.

Khan.I.\& Kapoor.A.K.,2015.Cognitive Dynamics in Decision Making a Population Group of South West India, The Int.J. of Technology Innovations and Research, Vol 15.

Khan.I.\&Kapoor.A.K.,2015. 'Neuroanthropological profile in a population group of Karnataka'. The Int. J.of Humanities and Social Studies, Vol.3, Issue 3.

Khan.I.\&Kapoor.A.K.2015.Aspect of Cognitive Dynamics with reference to sex in a population group of Karnataka, Int.J. of Multi disciplinary Research and Development,Vol.2,Issue 4.

Lende, H.\&, Downey, Greg,2012.The Encultured Brain: An Introduction to Neuroanthropology, MIT press.

McDermott,2008. Basics of Emotional Intelligence. American society for Training and Development,Vol.25,Issue 810.

Noorbakhsh et al,2010. Emotional Intelligence and coping styles of stress. J. Procedia-Social and Behavioral Sciences,Vol.5,Pg818-822. Tylor et al,2004.Emotional Intelligence: Theory, Findings and Implications.J.PsychologicalInquiry. 


\section{ACKNOWLEDGEMENT}

My heartfelt thank you to Professor A. K. Kapoor, my supervisor for his support and guidance all throughout the journey of the research work. Financial assistance from University of Delhi is greatly acknowledged. Sincere vote of thanks to the people of Allahabad for extending their cooperation for the collection of research data and information. 